\title{
OVOS DE HELMINTOS ENCONTRADOS EM FEZES DE AVES SILVESTRES
}

Yuri Jorge Ornelas Melo ${ }^{1}$, Kaline Ogliari', Henrique Trevizoli Ferraz², Rafaela Assis Oliveira $^{3}$, Priscila Taciani Bomtempo Aguiar ${ }^{3}$

Médicos Veterinários, Universidade Federal de Goiás/Regional Jataí, Jataí, Brasil. (yurimoj@gmail.com)

Doutor, Docente, Universidade Federal de Goiás/Regional Jataí, Jataí, Brasil. ${ }^{3}$ Mestrandas em Biociência Animal, Universidade Federal de Goiás/Regional Jataí, Jataí, Brasil.

\section{Recebido em: 06/04/2019 - Aprovado em: 10/06/2019 - Publicado em: 30/06/2019 DOI: 10.18677/EnciBio_2019A94}

\begin{abstract}
RESUMO
Os helmintos são comumente relatados em infecções de aves silvestres. Essas infecções parasitárias geralmente não desencadeiam quadros clínicos, mas podem ter curso fatal em alguns casos. A mortalidade depende de fatores como estresse em cativeiro, ambiente inadequado e contato com hospedeiros intermediários. Os ovos dos endoparasitas são eliminados junto às fezes das aves hospedeiras. $O$ diagnóstico das infecções é feito através de análises coproparasitológicas. Técnicas laboratoriais de microscopia direta, flutuação e sedimentação espontânea do material fecal são utilizadas para a detecção dos ovos. Por possuírem diferenças morfológicas no tamanho, espessura e formato, os ovos possibilitam a identificação dos helmintos parasitas de aves silvestres. Medidas de prevenção e controle envolvem desinfecção ambiental e garantia da imunocompetência das aves, além de se evitar recintos compartilhados com diferentes espécies de aves. O tratamento deve ser determinado de acordo com os resultados das análises coproparasitológicas, que devem ser repetidas com certa frequência.
\end{abstract}

PALAVRAS-CHAVE: análises, aves, parasitologia

\section{HELMINTHS EGGS FOUND IN WILD BIRDS FECES}

\begin{abstract}
Helminths are commonly reported in wild bird infections. These parasitic infections usually don't cause clinical signs but may have a fatal course in some cases. Mortality depends on factors such as captive stress, inadequate environment and contact with intermediate hosts. The endoparasites eggs pass out of the avian host with the feces. The diagnosis of the infections is done through coproparasitological analysis. Laboratory techniques such as direct microscopy, flotation and spontaneous sedimentation of fecal material are used for the detection of the eggs. Due to the morphological differences in size, thickness and shape, the eggs enable the identification of the parasites. Prevention and control measures involve environmental disinfection, ensuring the immunocompetence of the birds and avoiding enclosures with different species of wild birds. The treatment must be
\end{abstract}


determined according to the results of the coproparasitological analysis, which must be periodically repeated.

KEYWORDS: analysis, birds, parasitology

\section{INTRODUÇÃO}

Os helmintos são endoparasitas comumente relatados em aves silvestres, sendo prejudiciais especialmente para aves cativas (SNAK et al. 2014). Esses parasitam, na maioria dos casos, o trato gastrointestinal das aves, liberando ovos junto às fezes dos hospedeiros (BOWMAN, 2014).

Os quadros clínicos gerados pelas diversas espécies de helmintos das aves variam de assintomáticos a quadros envolvendo diarreia, prostração e baixo desempenho reprodutivo (LIMA et al., 2017; PEREZ-GOMEZ et al., 2018). Quadros clínicos graves são mais frequentes em aves cativas mantidas em zoológicos e criadouros, devido a higiene inadequada, área restrita e contato com animais de vida livre (SNAK et al. 2014). Além disso, podem cursar com quadros de alta mortalidade de indivíduos. Normalmente, a morbidade e mortalidade das populações de aves infectadas por helmintos vão depender de fatores relacionados à condição imune do hospedeiro, espécie do parasita e condições sanitárias do ambiente (SANTOS et al., 2015; AYRES et al., 2016).

Como os sinais clínicos são inespecíficos e muitas vezes não estão presentes, o diagnóstico das infecções por helmintos é feito a partir de análises coproparasitológicas, que devem ser mantidas atualizadas. Algumas das técnicas mais utilizadas nas análises do material fecal das aves são a microscopia direta e as técnicas de sedimentação e flutuação (SNAK et al. 2014; TAYLOR et al., 2016). Essas permitem identificar os ovos dos helmintos pela da morfologia variada que apresentam, como diferentes tamanhos, espessura da casca e formato (BOWMAN, 2014).

Dessa forma, é possível determinar o protocolo terapêutico mais eficiente a ser utilizado no tratamento. O controle e a prevenção das infecções por helmintos são feitos através da desinfecção do ambiente e evitando que as aves tenham contato com os hospedeiros intermediários (CUBAS et al., 2014). Objetivou-se com o presente trabalho apresentar as características morfológicas dos ovos dos principais gêneros de helmintos parasitas de aves silvestres, importantes para identificação do parasitismo, além dos procedimentos diagnósticos, de controle e tratamento relatados pela literatura consultada.

\section{CARACTERIZAÇÃO DOS HELMINTOS}

Os helmintos são animais eucariotos de vida livre ou parasitária. Os de vida parasitária são endoparasitas encontrados em plantas, aves, répteis, peixes, anfíbios e mamíferos, incluindo seres humanos. Esses possuem adaptações em seus sistemas para garantir a sobrevivência no organismo do hospedeiro (SCHMIDT et al., 2015; TORTORA et al., 2017).

Os helmintos de maior importância para a medicina veterinária são divididos em dois filos: Nemathelminthes e Platyhelmintes (TAYLOR et al., 2016). Dentro destes, as classes de maior relevância no parasitismo de aves são: Nematoda, também conhecidos como nematódeos (filo Nemathelminthes), Trematoda e Cestoda, chamados respectivamente de trematódeos e cestódeos (ambas pertencentes ao filo Platyhelmintes) (BOWMAN, 2014). 


\section{NEMATHELMINTHES}

Dentro do filo Nemathelminthes, a classe Nematoda contém a maior quantidade de parasitas de animais endotérmicos. Esses parasitas são chamados de "vermes redondos" por possuírem o corpo cilíndrico, alongado e não segmentado (BAKER, 2007). Possuem simetria bilateral e são revestidos por um envoltório incolor chamado cutícula, que contém glicoproteínas envolvidas na interação parasita-hospedeiro (URQUHART et al., 1998).

A maioria dos nematódeos é ovípara. Normalmente são dióicos, com dimorfismo sexual, sendo as fêmeas maiores que os machos (BAKER, 2007). Existem ainda espécies hermafroditas e outras partenogênicas. Os adultos podem variar de menos de 0,5 mm a 10,0 $\mathrm{m}$ (ROBERTS et al., 2013).

O sistema digestório desses parasitas é completo e tubular. Apresentam esôfago de formato variado e boca, localizada na porção anterior, que se abre em um orifício contendo até três lábios ou na chamada cápsula bucal com dentes capazes de se alimentar da mucosa intestinal do hospedeiro (TAYLOR et al., 2016).

O sistema reprodutor masculino é composto por um testículo e ducto deferente. As espículas copulatórias conduzem o esperma para o útero da fêmea enquanto a bolsa copulatória a envolve durante a cópula (BOWMAN 2014; TORTORA et al., 2017).

O sistema reprodutor da fêmea consiste em um tubo filamentoso, contendo ovário(s), oviduto, útero e vagina, terminando na vulva. Entre o fim do útero e o início da vagina algumas espécies apresentam um órgão muscular denominado ovojetor, responsável pela postura dos ovos, geralmente eliminados junto às fezes do hospedeiro (BAKER, 2007; TAYLOR et al., 2016).

O ciclo de vida pode incluir a participação de hospedeiro intermediário ou não, chamado ciclo indireto e direto, respectivamente. Os hospedeiros intermediários geralmente são insetos ou minhocas. Geralmente ocorre desenvolvimento do parasita antes da infecção do hospedeiro definitivo, no bolo fecal, onde os ovos são excretados, ou no hospedeiro intermediário (URQUHART et al., 1998).

Durante o ciclo evolutivo, os parasitas nematódeos realizam quatro mudas, passando por cinco estádios larvais (L1, L2, L3, L4 e L5), sendo a última o adulto imaturo (BOWMAN, 2014). A Figura 1 representa o ciclo evolutivo dos nematódeos, incluindo as fases de desenvolvimento do ovo mais comumente vistas nos procedimentos diagnósticos, que são: célula única, mórula e embrião vermiforme.

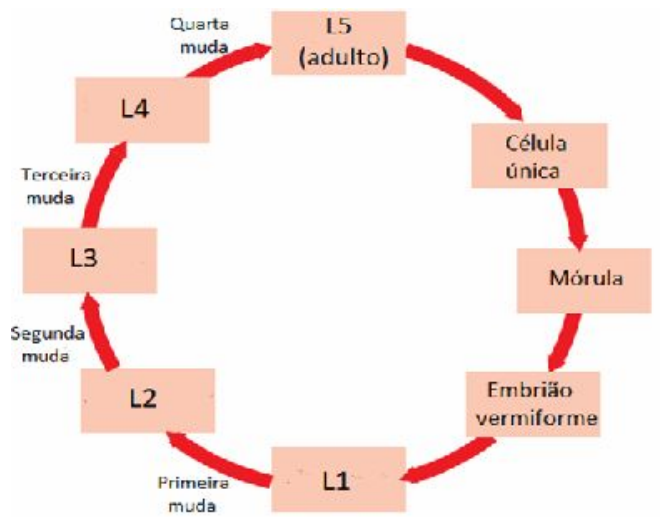

FIGURA 1 - Ciclo evolutivo dos nematódeos Fonte: adaptado de BOWMAN (2014) 
A infecção dos hospedeiros definitivos a partir do ciclo direto ocorre, na maioria das vezes, pela L3. Isso se dá por ingestão da larva de vida livre ou por penetração ativa da larva na pele, podendo ainda ocorrer a ingestão do ovo contendo a L3 (TAYLOR et al., 2016). Nos ciclos evolutivos indiretos, as duas primeiras mudas ocorrem no hospedeiro intermediário. Sendo assim, a infecção do hospedeiro definitivo ocorre após ingestão dos insetos e minhocas ou por inoculação da L3 quando se tem um inseto hematófago como hospedeiro intermediário (BOWMAN, 2014).

No caso dos parasitas gastrointestinais, o desenvolvimento no hospedeiro definitivo ocorre inteiramente no lúmen intestinal ou com pequeno movimento na mucosa (URQUHART et al., 1998). Os ovos dos nematódeos variam no tamanho, formato e espessura da casca, que são fatores importantes para o diagnóstico das infecções parasitárias a partir da análise das fezes do hospedeiro (JACOBS et al., 2016). O formato dos ovos é determinado pelo útero sendo que células uterinas atuam secretando conteúdo adicional para a formação das cascas (ROBERTS et al., 2013).

Normalmente, os ovos consistem em três camadas. A membrana mais interna é fina e de composição lipídica, sendo impermeável. A camada intermediária é responsável pela rigidez do ovo, tendo composição quitinosa. Em algumas espécies de nematódeos essa camada termina nos chamados opérculos, em uma ou ambas extremidades do ovo. A camada mais externa é proteica e espessa (TAYLOR et al., 2016). A espessura da casca, de acordo com Taylor et al. (2016), parece estar relacionada com a proteção do ovo contra dessecação ambiental e consequente resistência do mesmo no ambiente. Segundo Roberts et al. (2013), ovos de casca mais espessa podem se manter aptos à infecção por anos fora do hospedeiro.

Em muitas espécies de nematódeos de mamíferos, répteis e aves, os ovos se rompem apenas dentro do hospedeiro, porém eles se mantêm intactos e inativos até que recebam os devidos estímulos, como temperatura, concentração de dióxido de carbono e pH ideais (ROBERTS et al., 2013). Em outros casos a eclosão ocorre no ambiente, sendo controlada por umidade e temperatura. Nas fezes as larvas encontram microclima ideal, com elevada umidade para seu desenvolvimento, mesmo em ambientes secos (TAYLOR et al., 2016). Os helmintos nematódeos de maior frequência e importância para aves silvestres pertencem aos gêneros Ascaridia, Capillaria, Heterakis, Contracaecum e Eustrongylides (MELO et al., 2013; BARATHIDASAN, 2014; SANTOS et al., 2015; AYRES et al., 2016).

\section{Gênero Ascaridia}

Nematódeos do gênero Ascaridia acometem praticamente todas as aves, tanto silvestres quanto domésticas. Causam infecções graves e muitas vezes fatais em aves exóticas mantidas em cativeiro. São vermes compridos (fêmeas podem chegar a 12,0 cm de comprimento), robustos e de coloração branca opaca (BENEZ, 2004; TAYLOR et al., 2016). Os parasitas adultos do gênero Ascaridia se localizam no lúmen intestinal das aves e as larvas no oviduto, intestino e pulmões. Do oviduto podem migrar para a cloaca e haver inclusão das larvas nos ovos da ave hospedeira (ROBERTS et al., 2013).

O ciclo biológico é direto, sendo que gafanhotos e minhocas podem atuar como hospedeiros de transporte. O reservatório da infecção fica no solo, onde estão ovos livres, ou nos hospedeiros transportadores (ATKINSON et al., 
2008). Os ovos têm formato oval e apresentam a casca lisa, como mostrado na Figura 2. São bastante parecidos com ovos de Heterakis, outro gênero de ascarídeo comum em aves (ZAJAC; CONBOY, 2012).

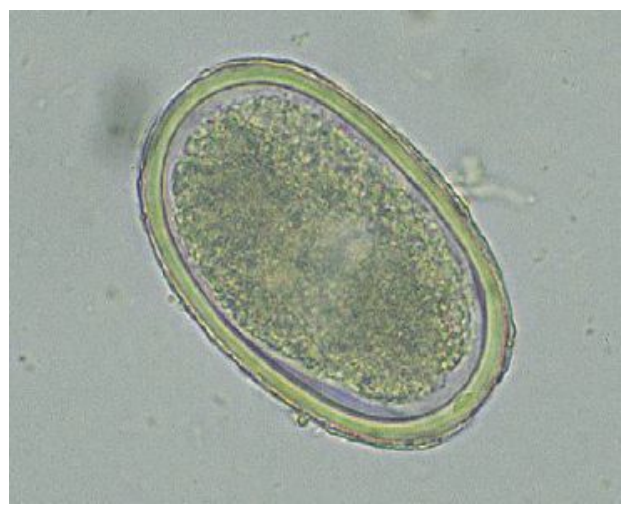

FIGURA 2 - Ovo de Ascaridia sp.

Fonte: CONBOY ; ZAJAC (2012)

Os ovos se tornam infectantes a partir de três semanas em temperatura ambiental ótima. Ambientes quentes e secos podem destruí-los. Os ovos conseguem se manter viáveis por vários meses em condições de alta umidade. Em galinhas o período pré-patente varia de cinco a seis semanas e em pintinhos cerca de oito semanas. Os vermes na fase adulta podem viver aproximadamente um ano (TAYLOR et al., 2016).

São frequentemente relatados em aves cativas da ordem Psittaciformes, como araras e periquitos, sendo um dos parasitas mais importantes de papagaios mantidos em cativeiro (HOFSTATTER e GUARALDO, 2015). Segundo Melo et al. (2013), as espécies de Ascaridia mais comuns nessa ordem são Ascaridia platyceri e $A$. hermafrodita. Além disso, esse gênero de helmintos está entre os parasitas mais comumente encontrados em aves Columbiformes de criadouros, como pombos e rolas (LIMA et al., 2017).

A espécie Ascaridia brasiliana está entre os nematódeos de maior importância clínica para aves Tinamiformes, como as perdizes, podendo causar enterite catarral crônica e anemia. Esse gênero de parasitas não é comum em pequenos Passeriformes (CUBAS et al., 2014).

\section{Gênero Heterakis}

Além de infecções em aves de produção, nematódeos do gênero Heterakis podem ter impacto negativo em aves cativas de zoológicos e aves silvestres de vida livre, sendo amplamente distribuídos pelo mundo, assim como Ascaridia spp. (TAYLOR et al., 2016).Pelo menos uma espécie de Heterakis já foi relatada em cada continente do mundo, exceto na Antártida, sendo que esse gênero já foi encontrado em, pelo menos, 107 espécies de aves silvestres, incluindo diversas aves brasileiras da ordem Tinamiformes. (ATKINSON et al., 2008).

Os adultos chegam até $1,5 \mathrm{~cm}$ e parasitam o ceco dos hospedeiros definitivos. Ficam encapsulados em nódulos na mucosa, com acesso ao lúmen, aonde são liberados os ovos. O ciclo de vida é direto. Gafanhotos e moscas domésticas podem servir de carreadores mecânicos para os ovos (ROBERTS et al., 2013). Geralmente não são nematódeos patogênicos, porém podem carrear o protozoário Histomonas meleagridis. Infecções concomitantes de 
Heterakis gallinarum e $H$. meleagridis podem causar graves ulcerações na mucosa cecal de perus e pavões (ROBERTS et al., 2013; COSTA et al., 2018).

Em temperatura ideal o ovo torna-se infectante em cerca de duas semanas e se mantem viável por vários meses no solo. Minhocas podem atuar como transportadores, onde os ovos não eclodem, ou como hospedeiros paratênicos, situação em que os ovos eclodem nas minhocas, a L3 penetra em seus tecidos e permanece até a ingestão pelo hospedeiro definitivo. A diferenciação dos ovos de Heterakis spp. e de Ascaridia spp. é difícil, sendo feita principalmente pelo tamanho, uma vez que os ovos de Heterakis spp. são menores (TAYLOR et al., 2016). Como mostrado na Figura 3, os ovos se apresentam ovoides, de casca lisa e normalmente sem segmentação do conteúdo (BOWMAN, 2014).

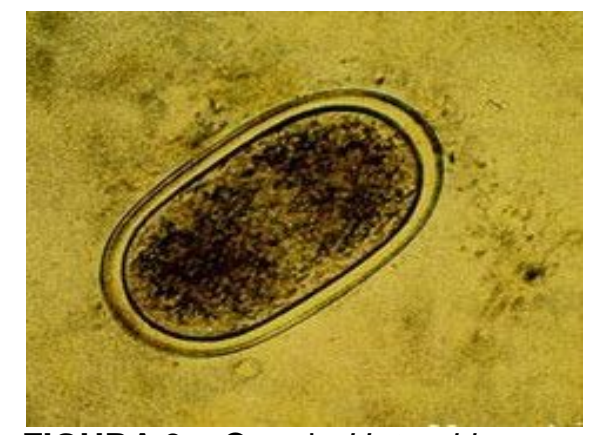

FIGURA 3 - Ovo de Heterakis sp.

Fonte: Royal Veterinary College

Parasitas desse gênero são comuns em aves da ordem Galliformes mantidas em cativeiro e já foram relatados em zoológicos e criadouros comerciais em papagaios (HOFSTATTER e GUARALDO, 2015), gavião-carijó, trinca-ferro (MARIETTO-GONÇALVES et al., 2009) e calopsita (LIMA et al., 2017). De acordo com Santos et al. (2008) podem ocorrer quadros de diarreia e morte súbita nas aves devido a infecção pelo protozoário Histomonas meleagridis, sendo os parasitas identificados na necropsia.

Um surto de histomoníase em pavões-indianos foi relatado por COSTA et al. (2018) em uma propriedade no município de Uruguaiana, Rio Grande do Sul, que culminou com a morte de 8 pavões. Na necropsia constataram a presença de Heterakis gallinarum.

\section{Gênero Capillaria}

Os nematódeos deste gênero são esbranquiçados e finos, com aspecto remetendo a fios de cabelo. As fêmeas das espécies de Capillaria comuns em aves variam de 15,0 a $80,0 \mathrm{~mm}$ e os machos de 10,0 a 25,0 mm de tamanho. Minhocas atuando como hospedeiro intermediário no ciclo de vida são comuns em algumas espécies destes parasitas, como na $C$. caudinflata. Nos demais, o ciclo é direto (ATKINSON et al., 2008).

Classificar esses nematódeos pode ser difícil devido a alterações na classificação taxonômica e nos diversos sinônimos que existem para os grupos de Capillaria, sendo que algumas espécies recebem o nome genérico Eucoleus (TAYLOR et al., 2016). Atkinson et al. (2008) classificaram apenas como capilarídeos nematódeos vários gêneros, incluindo Capillaria e Baruscapillaria. Segundo os mesmos, a maioria das espécies de capilarídeos já foi relatada em, pelo 
menos, duas espécies de aves, sendo que algumas acometem aves de diversas ordens, como o Eucoleus contortus.

Este gênero já foi encontrado na maioria das espécies de aves, incluindo espécies das ordens Psittaciformes, Galliformes e Passeriformes. Parasitam o trato gastrointestinal, podendo acometer outros órgãos, mas normalmente se desenvolvem sem migração (TAYLOR et al., 2016; BALLARD; CHEEK, 2017). Benez (2004) relatou que Capillaria sp. pode ser encontrada no papo, esôfago, próventrículo, moela e intestinos, incluindo o ceco, causando inflamações e ulcerações nos locais de fixação. A larva de primeiro estádio infectante, mostrada na Figura 4c, se desenvolve no ovo em cerca de três ou quatro semanas (TAYLOR et al., 2016).
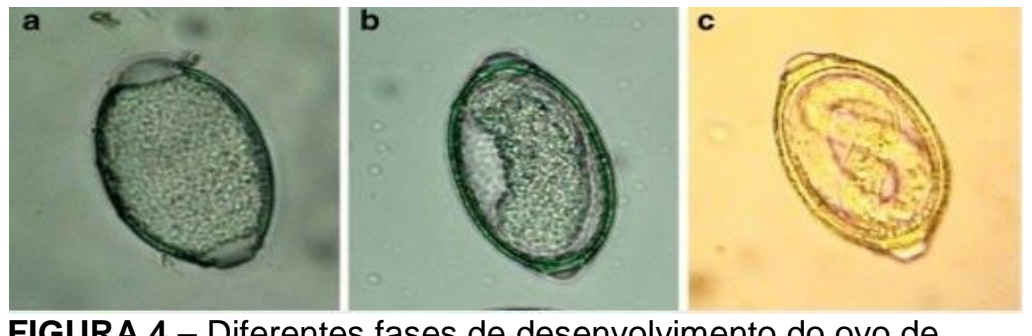
FIGURA 4 - Diferentes fases de desenvolvimento do ovo de Capillaria obsignata. (A) - Ovo não embrionado, (B) - Embrião móvel e (C) - estádio larval infectante
Fonte: TIERSCH (2012)

Os ovos possuem opérculos nas duas extremidades, sendo então chamados de bioperculados. Possuem o formato mais próximo a um barril e se apresentam mais transparentes e levemente amarelados na microscopia, como mostrado na Figura 5 (URQUHART et al., 1998).

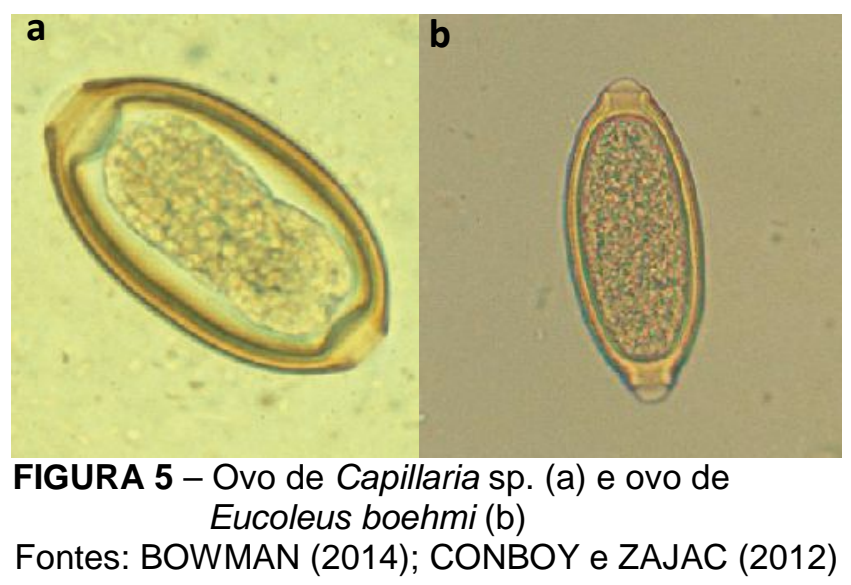

O gênero Capillaria está entre os parasitas mais encontrados em fezes de aves silvestres cativas, principalmente em aves da ordem Psittaciformes. No estudo de Hofstatter e Guaraldo (2015), Capillaria sp. foi o parasita mais abundantes nas amostras de araras, papagaios e maiatacas mantidos em zoológicos. No Centro de Triagem de Animais Silvestres em Vitória da Conquista, Bahia, Oliveira et al. (2016) constataram Capillaria sp. como o parasita mais encontrado nas amostras de periquitos da caatinga, sendo relatados também em papagaios verdadeiros (Amazona aestiva) e gaviões carcarás (Caracara plancus). São encontrados também em várias espécies de aves Passeriformes insetívoras, granívoras, onívoras e nectarívoras (TULLY et al., 2010). 
A capilariose, doença causada pela infecção por Capillaria sp., é um grande problema para tucanos (Ramphastos spp.) e araçaris (Pteroglossus spp.), sendo a principal doença que acomete essas aves mantidas em cativeiro no Brasil. É menos comum em aves domiciliadas e mais frequente em zoológicos com recintos compartilhados e com altas densidades de aves. Os quadros clínicos estão relacionados com caquexia, fezes mucoides, polifagia e infecções secundárias, podendo causar alta mortalidade (CUBAS et al., 2014). Estes autores citam ainda a ocorrência de Capillaria penidoi em perdizes criadas em piso de terra que apresentaram emagrecimento progressivo, caquexia e anemia, uma vez que esses nematódeos podem manifestar quadros de enterite catarral crônica e inglúvio e mucosas hemorrágicas. São mais frequentes nas aves que mantém contato maior com o solo, apesar dos parasitas não estarem presentes nas perdizes criadas em piso de concreto.

\section{Gênero Eustrongylides}

Esses parasitas são largos e avermelhados, possuindo de 4,0 a 15,0 mm. Podem causar peritonites crônicas em aves adultas, além de diarreia hemorrágica e infecções secundárias fatais em indivíduos jovens (ATKINSON et al., 2008). Têm distribuição geográfica ampla, assim como o leque de espécies de aves que parasitam. As aves se infectam através da ingestão de peixes, que atuam como hospedeiros intermediários. Minhocas, pequenos mamíferos e anfíbios podem atuar como hospedeiros paratênicos (MELO et al., 2013).

Esses nematódeos causam adesões e lesões por perfuração no estômago, intestinos, cloaca, proventrículo, sacos aéreos e peritônio. Os ovos de parasitas desse gênero são resistentes a variações climáticas, embora o tempo de desenvolvimento possa ser afetado pela temperatura e salinidade do ambiente (ATKINSON et al., 2008; TAYLOR et al., 2016).

As aves piscívoras atuam como hospedeiros definitivos desse gênero de parasita, portanto a infecção tem maior importância para socós, garças, cormorões, entre outras aves que se alimentam de peixes e anfíbios (MELO, et al. 2016).

Os ovos maduros apresentam casca bem definida e espessa. $\mathrm{Na}$ microscopia eletrônica é possível observar ovos em processo de divisão embrionária, como mostrado na Figura 6. A espécie Eustrongylides ignotus é a mais comumente relatada em aves que se alimentam de peixes (SPALDING; FORRESTER, 1993).

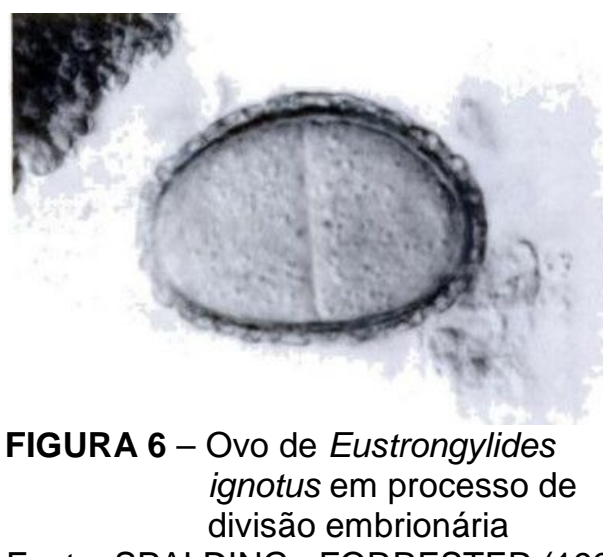

Fonte: SPALDING ; FORRESTER (1993) 
A espécie Eustrongylides ignotus pode causar eustrogilidiose em garças e cegonhas através da ingestão de peixes infectados. A infecção causa aderências, peritonite, anorexia e lesões fibrosas sobre órgãos como fígado e ventrículo, que podem ser palpadas externamente (CUBAS et al., 2014).

\section{PLATYHELMINTES}

Parasitas desse filo se diferenciam dos nematódeos por não serem revestidos por cutícula e não possuírem cavidade corporal (acelomados). Têm simetria bilateral e são achatados dorso-ventralmente, sendo popularmente chamados de "vermes achatados". A maioria dos platelmintos é parasita e engloba as classes Cestoda e Trematoda (BOWMAN, 2014; TORTORA et al., 2017).

Possuem a maior parte do corpo composta por parênquima, onde estão distribuídos os órgãos, fibras musculares, células secretórias (que armazenam alimentos ou produtos metabólicos) e células regenerativas. A epiderme larval é substituída por um sincício de células fusionadas que recobrem os parasitas adultos (BAKER, 2007). O sistema digestório, quando presente, é composto por um saco sem fundo possuindo apenas o orifício bucal. Através da boca são regurgitadas substâncias não digeridas. Os resíduos são eliminados através de sistemas tubulares que desembocam no poro excretório (BOWMAN, 2014).

A maioria dos platelmintos é monoica, sendo algumas espécies dioicas. Os hermafroditas são capazes de fertilizar seus próprios ovos, podendo haver fertilização cruzada também. A reprodução assexual também é comum nesse grupo de nematódeos. Os ovos são expelidos através do poro genital, normalmente localizado na superfície ventral desses parasitas (ROBERTS et al., 2013).

\section{CLASSE TREMATODA}

Dentro da classe dos trematódeos há uma subclasse contendo os parasitas de maior importância para a medicina veterinária, chamada Digenea. Esta parasita animais vertebrados e em seu ciclo de vida são necessários moluscos atuando como hospedeiros intermediários. Os ovos são eliminados dos hospedeiros definitivos pelas excretas das aves (BAKER, 2007; ATKINSON et al., 2008).

O sistema reprodutor masculino consiste em um par de testículos, um par de ductos deferentes, vesícula seminal e o cirro, o pênis primitivo dos trematódeos que termina no poro genital comum, capaz de transferir esperma para o sistema reprodutor feminino. Este conta com ovário único, um oviduto, que se expande, formando o oótipo, e o útero. No hospedeiro intermediário ocorre reprodução assexuada e nas aves sexuada (ROBERTS et al., 2013).

Os ovos são fertilizados no oviduto. No oótipo adquirem substâncias secretadas por glândulas vitelínicas e uma casca. No útero os ovos se desenvolvem, tendo suas cascas fortalecidas e tornando-os aptos a eclodirem assim que forem expelidos. A casca proteica confere coloração amarelada aos ovos maduros. $\mathrm{Na}$ maioria das espécies os ovos possuem formato oval e alguns apresentam opérculo em uma das extremidades (TAYLOR et al., 2016).

Nas aves, os adultos podem ser encontrados no trato gastrointestinal, incluindo esôfago, intestinos, ceco e cloaca, além do trato respiratório, como na traqueia e sacos aéreos. Os ovos de trematódeos contêm um embrião ou um miracídio, dependendo do estado de maturação dos mesmos, e são relativamente pequenos (ROBERTS et al., 2013).

No ciclo de vida dos trematódeos de importância para as aves, os ovos são eliminados juntamente com as fezes da ave hospedeira 
definitiva, atingindo o solo ou a água, momento em que o opérculo se abre. As fases de desenvolvimento básico dos trematódeos estão esquematizadas na Figura 7. Eles podem passar por dois hospedeiros intermediários, que normalmente vão ser caramujos, antes de serem ingeridos pelas aves e originarem os vermes adultos após algumas semanas nos locais de preferência (ATKINSON et al., 2008).

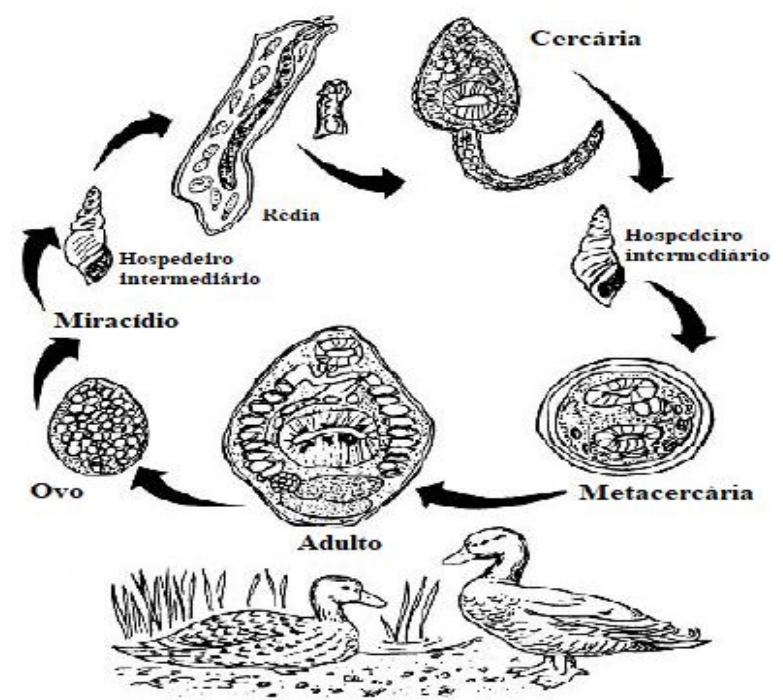

FIGURA 7 - Fases do ciclo evolutivo de trematódeos de importância para aves

Fonte: adaptado de ATKINSON et al. (2008)

\section{Família Echinostomatidae}

De acordo com TAYLOR et al. (2016), os trematódeos da família Echinostomatidae parasitas de aves pertencem aos gêneros Echinostoma, Echinoparyphium e Hypoderaeum. Ainda segundo esses autores, as cercárias desses parasitas se encistam nos rins de sapos, que servem como hospedeiros intermediários, assim como os moluscos. O período pré-patente varia de uma a duas semanas e possuem 4,0 a 20,0 mm de comprimento.

As espécies Echinostoma revolutum e Hypoderaeum conoideum infectam patos e aves próximas, como gansos e perdizes (ATKINSON et al., 2008). E. revolutum pode infectar pombos e, ocasionalmente, seres humanos (TAYLOR et al., 2016). A Figura 8 mostra um ovo de trematódeos do gênero Echinostoma.

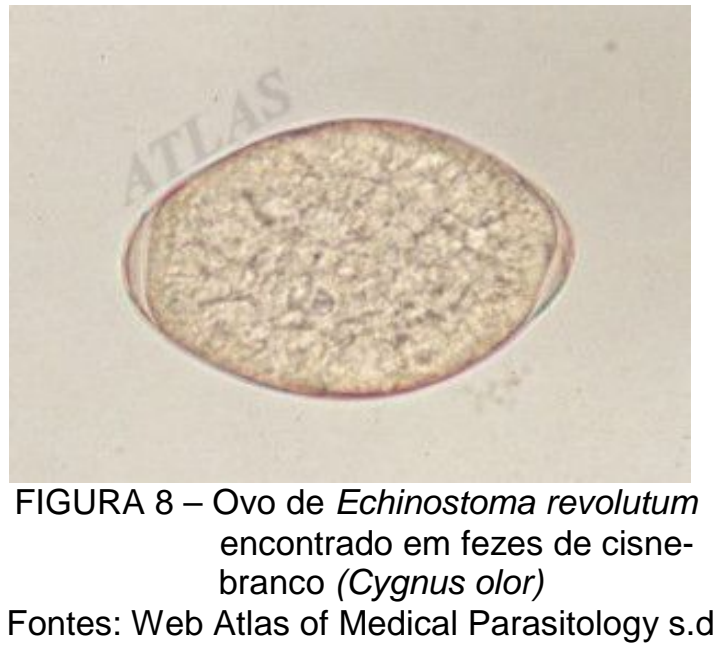


No Brasil, a espécie Echinostoma revolutum já foi encontrada em várias aves Passeriformes, como o bem-te-vi, o cabeçudo e o sábia-bicolor no Parque Zoobotânico do Acre por Brito et al. (2017). Os mesmos relataram que altas cargas parasitárias dessa espécie parasita podem causar a morte das aves hospedeiras por perfuração intestinal.

\section{Família Schistosomatidae}

Esta família contém cerca de nove gêneros de importância para as aves, que são: Allobilharzia, Austrobilharzia, Bilharziella, Dendritobilharzia, Gigantobilharzia, Jilinobilharzia, Macrobilharzia, Ornithobilharzia e Trichobilharzia. Eles infectam principalmente aves das ordens Anseriformes, Ciconiiformes e Columbiformes, além de Passeriformes e Galliformes (ATKINSON et al., 2008).

Esses parasitas estão relacionados a habitats contendo água fresca. Por esse motivo são mais comuns em aves aquáticas e aves que têm maior contato com caramujos. As cercárias são capazes de penetrar no hospedeiro definitivo, atingindo a circulação sanguínea e completando o desenvolvimento em vasos sanguíneos de órgãos como fígado e intestinos (SCHMIDT et al., 2015).

Os ovos são liberados em grandes quantidades na circulação e devido à resposta imune do hospedeiro são deslocados para o espaço perivascular, atingindo finalmente o lúmen intestinal e sendo eliminados junto às fezes. Os sexos são separados nesses trematódeos e os ovos são produzidos pela fêmea apenas quando há contato com o macho (ROBERTS et al., 2013; BOWMAN, 2014).

A Figura 9a mostra um ovo de Trichobilharzia sp. encontrado em fezes de um pato-real (Anas platyrhynchos), evidenciando a morfologia simétrica e fusiforme do ovo, contando com uma extremidade mais arredondada e outra pontiaguda (SKIRNISSON; KOLAROVA, 2008). A Figura 9b mostra ovos de Gigantobilharzia sp. encontrados em excretas de ave Coraciiforme.

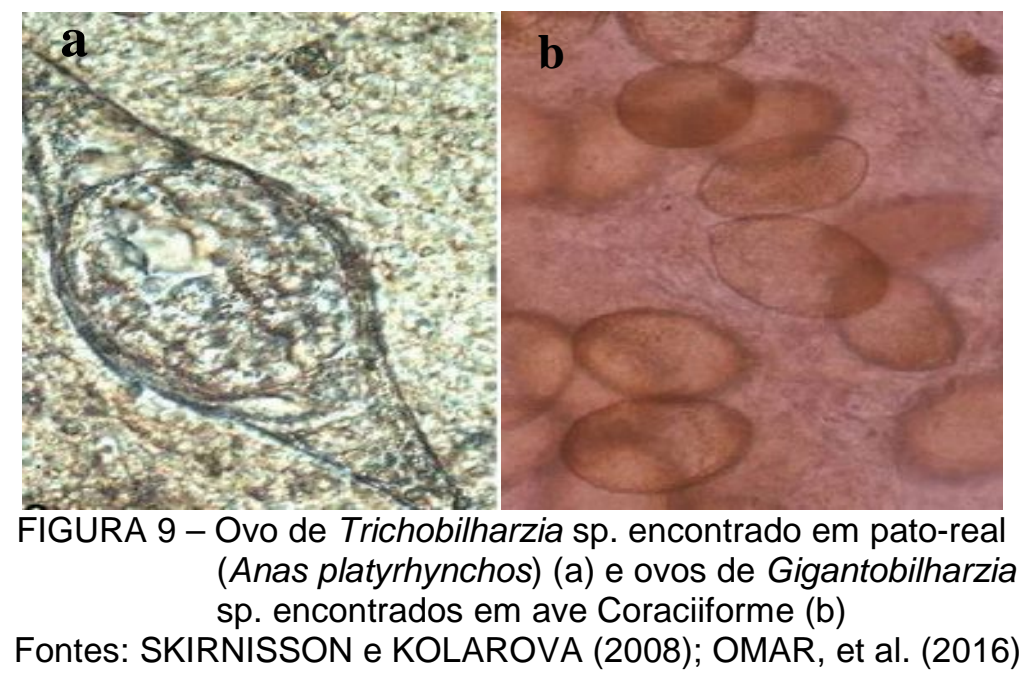

Pinto et al. (2012) levantaram a possibilidade de trematódeos da família Schistosomatidae que parasitam aves desenvolverem dermatite cercariana em seres humanos no Brasil. Isso é justificado pela ocorrência desses parasitas em aves e moluscos no território nacional, sendo que os gêneros Austrobilharzia, Bilharziella, Gigantobilharzia e Trichobilharzia já foram associados a quadros humanos de dermatite cercariana em outros países. Segundo os mesmos autores, os estudos em cima desses parasitas de aves são poucos e no Brasil, ENCICLOPÉDIA BIOSFERA, Centro Científico Conhecer - Goiânia, v.16 n.29; p.1139 2019 
trematódeos dessa família já foram relatados em algumas aves como o marrecão (Netta peposaca), pato-selvagem (Cairina moschata) e gaivotão (Larus dominicanus).

\section{CLASSE CESTODA}

Os cestódeos são parasitas com aspecto segmentado, comuns em aves, sendo que normalmente se localizam nos intestinos e outras porções do trato gastrointestinal, como na moela. Aves silvestres podem ser infectadas por um número grande de cestódeos, com encontro de dezenas a milhares de parasitas em uma única ave. Geralmente não desencadeiam quadros clínicos, exceto nas aves com infecções maciças ou imunodebilitadas (TAYLOR et al., 2016).

Variam de $1,0 \mathrm{~mm}$ a $1,0 \mathrm{~m}$ de comprimento, sendo que grande parte deles não passam de $10,0 \mathrm{~cm}$. São divididos em escólex (porção anterior), colo e proglótides. As proglótides mais anteriores são imaturas, as localizadas na porção intermediária são sexualmente maduras e as posteriores contêm os ovos, sendo eliminadas junto às fezes das aves, liberando seus ovos após a ruptura (BOWMAN, 2014). O ciclo de vida é indireto. As formas larvais são ingeridas por hospedeiros intermediários, muitas vezes sendo necessários dois hospedeiros para completar o ciclo. Os hospedeiros intermediários normalmente são moluscos, insetos, peixes e até roedores, no caso de espécies de cestódeos que infectam aves rapinantes (ATKINSON et al., 2008; TAYLOR et al., 2016).

Algumas famílias de cestódeos com espécies que infectam aves são: Gryporhynchidae, Mesocestoididae, Tetrabothriidea e Diphyllobothriidae (ATKINSON et al., 2008). As Figuras 10a e 10b mostram ovos de cestódeos da família Tetrabothriidea e a Figura 10c mostra um ovo de cestódeo da família Diphyllobothriidae, todos encontrados em fezes de pinguim-imperador (Aptenodytes forsteri).

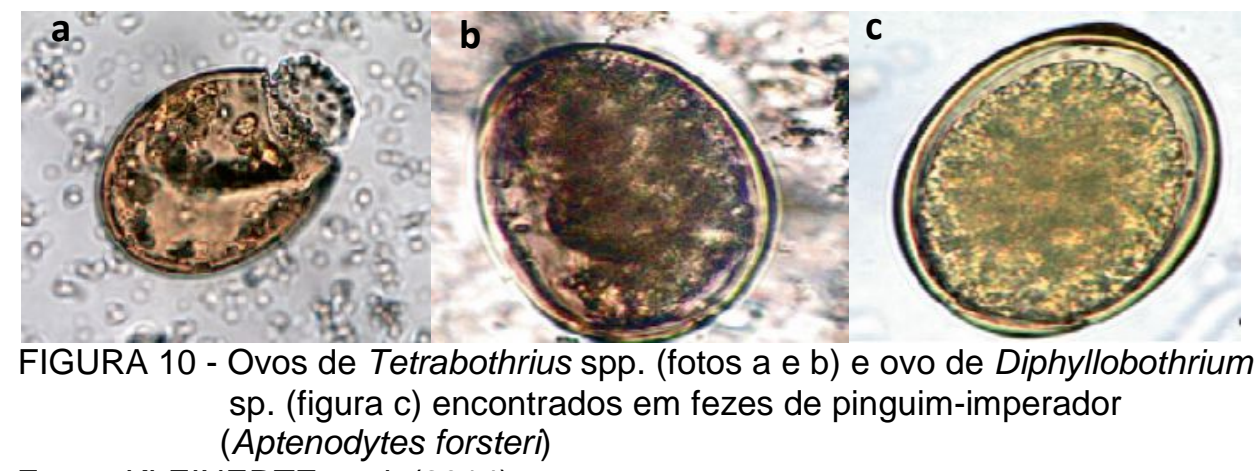

Fonte: KLEINERTZ et al. (2014)

Outros cestódeos que ocorrem em aves no Brasil são os pertencentes à família Davaineidae, como Raillietina spp. Estes são recorrentes em aves da ordem Galliformes, como perus e galinhas, além de existirem relatos em pombos (Columba livia) de vida livre (VAZ, et al. 2017). Cubas et al. (2014) relataram que são frequentes as infecções em psitacídeos, contando com formigas, moscas e gafanhotos como hospedeiros intermediários. Os autores também relataram que além dos ovos, as proglótides desses parasitas podem ser identificadas nas fezes.

Infecções por cestódeos são comuns em Passeriformes insetívoros, mas não são frequentes em aves granívoras. Nessas últimas, a infecção pode ocorrer 
quando as aves acidentalmente ingerem insetos junto às sementes ou quando são alimentadas com insetos pelos pais (TULLY, 2010).

\section{PATOGENIA E SINAIS CLÍNICOS}

As manifestações clínicas causadas pelo parasitismo de helmintos nas aves silvestres variam de infecções subclínicas à morte. Os parasitas podem prejudicar o desempenho reprodutivo de aves mantidas em cativeiro, além de afetar a nutrição e comportamento das mesmas (ATKINSON et al., 2008). Os sinais clínicos são inespecíficos e aparecem, principalmente, em aves com infecções maciças, jovens, imunodebilitadas, em condições de superpopulação e estresse. Essas condições também têm influência na mortalidade (CUBAS et al. 2014).

Aves silvestres de vida livre, normalmente, têm infecções de baixa intensidade. As lesões provocadas nos órgãos internos das aves estão relacionadas à interação parasita-hospedeiro ou a danos mecânicos nos tecidos durante a alimentação e migração dos parasitas. Os sinais mais comuns são perda de peso, diarreia, anorexia e letargia. Além disso, lesões fibrosas no fígado e mesentério podem ser encontradas na palpação abdominal (TULLY et al., 2010; CUBAS et al. 2014).

Os helmintos provocam enterites catarrais ou hemorrágicas, congestão intestinal em infecções maciças, espessamento e dilatação intestinais, intussuscepção e peritonite. Proventriculite, gastrite e hipoproteinemia podem ocorrer por conta dos helmintos espoliadores de sangue, além de ulcerações, que podem desenvolver colonização bacteriana e infecções secundárias (CONBOY; ZAJAC, 2012; SCHMIDT et al., 2015).

Algumas espécies de nematódeos, por exemplo, são capazes de secretar enzimas digestivas, como amilases e proteases, tornando-os aptos a alimentação através de células, fluidos teciduais e conteúdo do lúmen intestinal do hospedeiro (ROBERTS et al., 2013). Outros secretam substâncias anticoagulantes que permitem o contínuo extravasamento de vasos sanguíneos rompidos da mucosa do hospedeiro, podendo causar quadros de anemia (URQUHART et al., 1998).

\section{DIAGNÓSTICO}

Por exames coproparasitológicos é possível detectar a presença de diversos helmintos que parasitam diferentes sistemas das aves (TAYLOR et al., 2016). Os parasitas do sistema digestório liberam seus ovos no lúmen de diferentes porções do trato gastrointestinal, sendo esses eliminados junto às fezes da ave hospedeira. Larvas, cistos e, algumas vezes, os adultos também podem ser encontrados nas fezes. Ovos de parasitas do trato respiratório podem atingir o sistema digestório pela faringe (BOWMAN, 2014).

Através das características morfológicas dos ovos e das formas parasitárias encontradas nas fezes, os helmintos são identificados e, juntamente com o conhecimento do hospedeiro, são diagnosticadas as infecções parasitárias (CONBOY; ZAJAC, 2012). A primeira avaliação a ser feita é da aparência geral das fezes, observando cor, odor e consistência, sendo que em alguns casos estas podem apresentar-se diarreicas. Alguns cestódeos ou suas proglótides podem ser vistos macroscopicamente nas fezes (OTEGBADE; MORENIKEJIO, 2014).

As principais técnicas utilizadas para a identificação dos ovos de helmintos nas fezes são: microscopia direta, flutuação e sedimentação espontânea. A microscopia direta é a mais simples, sendo capaz de detectar a 
maioria dos ovos e formas parasitárias dos helmintos (TAYLOR et al., 2016). Consiste em colocar uma pequena quantidade de fezes em uma lâmina junto com uma gota de solução salina, espalhando o conteúdo entre a lâmina e uma lamínula. A lâmina é observada no microscópio nas objetivas de 10x e 40x. Essa técnica preserva larvas sensíveis de nematódeos. Resultados negativos são inconclusivos, uma vez que a quantidade de fezes analisada é pequena (CONBOY; ZAJAC, 2012; BOWMAN, 2014).

A técnica de flutuação é a mais utilizadas na medicina veterinária e consiste em diluir uma porção de fezes filtradas em soluções saturadas de sais ou açúcar. As soluções de flutuação possuem gravidade específica maior que a dos ovos e larvas e, por esse motivo, fazem com que eles flutuem. A diluição é colocada em um frasco com uma lamínula em cima. Após 10 minutos, no mínimo, a lamínula é retirada, colocada em uma lâmina e observada ao microscópio. Essa técnica é bastante útil para detecção de ovos mais leves, como os de nematódeos e cestódeos (CONBOY; ZAJAC, 2012; TAYLOR et al., 2016).

A técnica de sedimentação espontânea consiste em diluir as fezes em água, coar a diluição com gaze cirúrgica em um frasco e deixar repousar de duas a 24 horas. Uma pequena quantidade do conteúdo sedimentado é colocada em uma lâmina e observado no microscópio. Essa técnica é mais sensível que o esfregaço direto por dispensar boa parte dos debris fecais e concentrar os ovos, além de ser útil para detecção de ovos de trematódeos por serem mais pesados (NEVES, 2005).

É recomendado o uso de técnicas associadas para identificação de diferentes helmintos. Outros métodos diagnósticos são a técnica de Baermann, que concentra as larvas de nematódeos com o uso de água morna, a reação em cadeia da polimerase (PCR) (BOWMAN, 2014) e a cultura de larvas (CONBOY; ZAJAC, 2012).

Cubas et al. (2014) citaram a técnica de esfregaços de fezes corados pelos métodos de Ziehl Neelsen modificada, dimetil sulfóxido e Giemsa para identificação de proglótides e outras estruturas nas fezes.

A necropsia, por sua vez, é essencial para o conhecimento do perfil parasitário das aves, principalmente nos criadouros e zoológicos, visto que podem ocorrer quadros de morte súbita. Além disso, é comum indivíduos altamente parasitados e assintomáticos. Portanto, é importante colher amostras de diferentes porções do trato digestório, como intestino, proventrículo e moela, além de amostras do fígado e baço para análises histopatológicas e conhecimento dos endoparasitas presentes. Essa prática deve ser realizada independente da causa do óbito (CONBOY; ZAJAC, 2012; CUBAS et al. 2014).

\section{TRATAMENTO E CONTROLE}

Os fármacos mais utilizados para o controle de helmintos em aves são citrato de piperazina, praziquantel, ivermectina, levamisol, fembendazol e mebemdazol. O fembendazol tem bons resultados para Psitacídeos e Picídios, podendo ser incorporado à dieta. Esse medicamento, assim como o levamisol, tem obtido mais sucesso no tratamento contra Capillaria. Para quadros de capilarioses crônicas em tucanos e araçaris é recomendada a ingestão diária de $40 \mathrm{mg} / \mathrm{kg}$ de fembendazol por ave. O levamisol deve ser usado preferencialmente injetável na dose $20 \mathrm{mg} / \mathrm{kg}$ subcutâneo, com quatro aplicações com intervalo de uma semana. Para quadros agudos, além de tratamento de suporte e antibioticoterapia para infecções secundária, o fembendazol deve ser utilizado em 
suspensão na dose $50 \mathrm{mg} / \mathrm{kg}$ duas vezes ao dia por até uma semana. (CUBAS; GODOY, 2004; CUBAS et al., 2014).

Para patos, gansos e marrecos é recomendada administração única de fembendazol (20 mg/kg), exceto para infecções por Capillaria sp., onde recomendase administração por cinco dias, em dosagem maior $(50 \mathrm{mg} / \mathrm{kg})$. Praziquantel nessas aves, assim como para aves rapinantes, é eficaz contra cestódeos, sendo recomendado duas administrações, com 14 dias de intervalo (10 mg/kg para Anseriformes). Para trematódeos a administração é diária por 14 dias. Em aves Ciconiiformes o tratamento com fembendazol e/ou albendazol é feito durante 3 dias, sendo eficaz para nematódeos e trematódeos, apesar de não haver tratamento preconizado para eustrogilidiose nessas aves (ATKINSON et al., 2008; CUBAS et al., 2014).

De acordo com Tully et al. (2010) o tratamento de infecções por Capillaria pode ser mais complicado que o tratamento de infecções por ascarídeos. Marques et al. (2018) obtiveram bons resultados no tratamento de garça cinzenta (Nycticorax nycticorax) com capilariose. O tratamento foi feito com dose única $(20 \mathrm{mg} / \mathrm{kg})$ de levamisol por via subcutânea. Os autores ressaltaram a maior efetividade do uso dos antiparasitários levamisol e fembendazol e relataram que casos de necrose acentuada da parede intestinal das aves parasitadas resultam em pouco sucesso no tratamento.

É indicado alternância entre os anti-helmínticos para evitar resistência dos parasitas a longo prazo. Após o tratamento é importante refazer análises coproparasitológicas sucessivas, uma vez que a eliminação dos ovos ocorre de forma intermitente e para confirmar o sucesso do protocolo de tratamento estabelecido. Caso as análises consecutivas deem resultado negativo, o tratamento pode ser suspenso. Como medidas de controle e prevenção as aves parasitadas devem ser isoladas e os recintos, comedouros e bebedouros devem passar por limpeza e desinfecção frequentes para evitar reinfecção (TULLY et al., 2010).

Além disso, aves recém adquiridas devem passar por quarentena para evitar introdução de helmintos ao plantel (BENEZ, 2004). Cubas et al. (2014), recomendaram a realização de análises coproparasitológicas periódicas das aves do plantel, a cada três ou quatro meses, para manter o perfil parasitário das aves de criadouros e zoológicos atualizado e diagnosticar as infecções precocemente, facilitando o tratamento antiparasitário.

Outras práticas profiláticas que podem ser empregadas envolvem o uso de vassoura de fogo ou água fervente para limpar os recintos. Alguns ovos de helmintos apresentam alta resistência ambiental, dificultando a desinfecção e favorecendo a reinfecção de aves tratadas, como é o caso da Capillaria spp. Nesse caso, o uso do calor úmido é mais eficaz que a vassoura de fogo na destruição dos ovos. A remoção de minhocas do aviário também contribui para a eficácia da desinfecção. O ambiente mantido seco e limpo por três semanas muitas vezes é suficiente para que ocorra perda da infectividade dos ovos. Tucanos mantidos em cativeiro tendem a desenvolver o hábito de coprofagia. Portanto, na presença de Capillaria spp. deve-se limitar ao máximo o acesso dessas aves ao piso do recinto, pois podem acabar ingerindo os ovos dos parasitas nas fezes, além de hospedeiros intermediários. É recomendado ainda o uso de gaiolas suspensas, poleiros e outras formas de enriquecimento ambiental para que as aves permaneçam mais tempo nas partes altas do recinto. (TULLY, 2010; CUBAS et al., 2014). 
Segundo Snak et al. (2014) fatores estressantes como tamanho do recinto, fornecimento de alimento e água, podem predispor ao desenvolvimento das infecções parasitárias, assim como a presença de animais sinantrópicos, aves recém-chegadas aos criadouros, CETAS e zoológicos e aves que têm maior acesso ao chão.

Deve-se evitar ou diminuir o contato das aves com os hospedeiros intermediários, como moluscos, minhocas, moscas e gafanhotos, o que pode ser feito com o uso de moluscidas e outros pesticidas. Adicionalmente, deve-se evitar a ingestão de peixes ou roedores infectados pelas aves que se alimentam desses animais. O uso de comedouros e bebedouros suspensos reduzem as chances de contaminação da água e alimentos com as fezes. Recintos de zoológicos e criadouros com altas densidades de aves devem ser evitados. Recintos compartilhados com diferentes espécies de aves e outros animais também não são recomendados, assim como o contato de aves ou outros animais de vida livre com aves cativas (ATKINSON et al., 2008; TULLY et al., 2010; TAYLOR et al., 2016).

\section{CONSIDERAÇÕES FINAIS}

Os helmintos são frequentemente encontrados em diversas espécies de aves silvestres. Em situações predisponentes esses parasitas podem gerar quadros clínicos significativos, evidenciados mais comumente em aves mantidas em cativeiro, podendo levar à morte dos hospedeiros. Isto é preocupante, principalmente para aves ameaçadas de extinção. Pelas análises coproparasitológicas pode-se identificar o perfil parasitário devido às características morfológicas dos ovos e, com isso, direcionar as medidas de controle e tratamento.

É importante investir em medidas de prevenção das infecções parasitárias, garantindo um ambiente sanitário e livre de hospedeiros intermediários, além do bem-estar animal evitando condições estressantes e a imunodebilidade das aves cativas. Dessa forma, é possível reduzir os danos causados pelas infecções por helmintos e prevenir altos índices de mortalidade e morbidade nas populações de aves silvestres.

\section{REFERÊNCIAS}

ATKINSON, C. T.; THOMAS, N. J.; HUNTER, D. B. (Eds). Parasitic Diseases of Wild Birds. Ames: Blackwell, 2008. 595 p.

ARRONA-RIVERA, A. E.; HERNANDEZ-VELASCO, X.; BASURTO-ARGUETA, E. Identificación de Eustongylides tubifex (Nitzch in Rudolphi, 1819) (Nematoda: Dioctophymatidae) en una garza estriada (Butorides striata, Pelecaniforme: Ardeidae) en el humedal El Banco, Michoacán, México. Acta Zoológica Mexicana [online]. 2017, v. 33, n.2, p.181-187. Disponível em: <https://bit.ly/2YiFlo0>.

AYRES, M. C. C.; PEIXOTO, M. S. R.; SILVA, W. B.; GOMES, D. M.; NUNES, O. C.; et al. Ocorrência de parasitos gastrintestinais em Psitacídeos, mantidos em Parques Ecológicos na região metropolitana de Salvador, Bahia. Revista Brasileira de Medicina Veterinária. v. 32, n. 2, p. 133-136, abr/jun, 2016. Disponível em: https://www.revistas.ufg.br/vet/article/view/7164/8708 DOI: 10.5216/cab.v11i4.7164.

BAKER, D. G. (Ed.). Flynn's Parasites of Laboratory Animals. 2.ed. Hoboken: Blackwell Publishing, 2007. 813 p. 
BALLARD, B.; CHEEK, R. Exotic Animal Medicine for the Veterinary Technician. 3.ed. Ames: Wiley-Blackwell, 2017. 517 p.

BARATHIDASAN, R., SINGH, S. D.; GOWTHAMAN, V.; LATCHUMIKANTHAN A.; ARATHIDASAN; DHAMA, K. The first report of severe intestinal capillariosis caused by Baruscapillaria obsignata in farmed helmeted guinea fowls (Numida meleagris). VETERINARSKI ARHIV. v. 84, n. 5, p. 529-536, 2014.

BENEZ, S. M. Aves: criação, clínica, teoria e prática. 4.ed. São Paulo: Tecmedd, 2004. $600 \mathrm{p}$.

BOWMAN, D. D. Georgis' Parasitology for Veterinarians. 10.ed. Saint Louis: Elsevier Health Sciences, 2014. 499 p.

BRITO, A. S. de A.; GUILHERME, E.; SANTOS, F. G. de A.; MESQUITA, R. P. de; GOMES, F. A. Endoparasites of wild birds from Campus area and Zoobotanical Park, at the Federal University of Acre, Rio Branco - Acre. Arquivos de Ciências Veterinárias e Zoologia da UNIPAR, Umuarama, v. 20, n. 3, p. 117-122, jul./set. 2017.

COSTA, R. A.; PEREIRA, A. P. M.; SILVEIRA, C. S.; ANJOS, B. L. Infecção natural por Histomomonas meleagridis em pavões-indianos (Pavo cristatus). Acta Scientiae Veterinariae, v. 46, 2018.

CUBAS, Z. S.; GODOY, S. N. Algumas doenças de aves ornamentais. SciELO [online] 2004. Disponível em: https://bit.ly/2OVIk6f. Acesso em: 5 nov. 2018.

CUBAS, Z. S.; SILVA, J. C. R.; CATÃO-DIAS, J. L. Tratado de Animais Selvagens. 2.ed. São Paulo: ROCA, 2014. 2512 p.

HOFSTATTER, P. G.; GUARALDO, A. M. A. Parasitological survey on birds at some selected brazilian zoos. Revista Brasileira de Parasitologia Veterinária. Jaboticabal, v. 24, n. 1, p. 87-91, Mar. 2015. Disponível em: <http://dx.doi.org/10.1590/S1984-29612015005>.

JACOBS, D.; FOX, M.; GIBBONS, L.; HERMOSILLA, C. Principles of Veterinary Parasitology. Chichester: Wiley Blackwell, 2016. 726 p.

KLEINERTZ, S.; CHRISTMANN, S.; SILVA, L. M. R.; HIRZMANN, J.; HERMOSILLA, C.; TAUBERT, A. Gastrointestinal parasite fauna of Emperor Penguins (Aptenodytes forsteri) at the Atka Bay, Antarctica. Parasitology research, Berlin, v. 113. ago. 2014. Disponível em: <https://www.ncbi.nlm.nih.gov/pubmed/25164274> doi: 10.1007/s00436-014-4085-4.

LIMA, V. F. S.; BEZERRA, T. L.; ANDRADE, A. F.; RAMOS, R. A. N.; FAUTINO, M. A. G.; et al. Gastrointestinal parasites of exotic birds living in captivity in the state of Sergipe, Northeastern Brazil. Revista Brasileira de Parasitologia Veterinária, Jaboticabal, v. 26, n. 1, p. 96-99, Mar. 2017. Disponível em: <http://dx.doi.org/10.1590/s1984-29612016080>. 
MARIETTO GONÇALVES, G. A.; MARTINS, T. F.; LIMA, E. T.; LOPES, R. S.; ANDREATTI FILHO, R. L. Prevalência de endoparasitas em amostras fecais de aves silvestres e exóticas examinadas no Laboratório de Ornitopatologia e no Laboratório de Enfermidades Parasitárias da FMVZ-UNESP/Botucatu-SP. Ciência Animal Brasileira, v. 10, n. 1, p. 349-354, 2009.

MARQUES, S. M. T.; SILVA, B. Z.; BOLL, A. S.; SANTOS, E. D. R.; ALIEVI, M. M. Capilariose em savacu (Nycticorax nycticorax). Neotropical Helminthology. Lima Vol. 12, n. 1, jan/jun. 2018, p. 115-119.

MELO, C. M. F.; OLIVEIRA, J. B.; FEITOSA, T. F.; VILELA, V. L. R.; ATHAYDE, C. R.; DANTAS, A. F. M.; WAGNER, P. G. C.; FEBRONIO, A. B. Parasitas de Psittaciformes e Accipitriformes no estado da Paraíba, Brasil. Revista Brasileira de Parasitologia Veterinária, v. 22, n. 2, p. 314-317, abr./ jun. 2013. Disponível em: <http://dx.doi.org/10.1590/S1984-29612013000200051>.

MELO, F. T. V.; MELO, C. S. B.; NASCIMENTO, L. C. S.; GIESE, E. G.; FURTADO, A. P.; SANTOS, J. N. Morphological characterization of Eustrongylides sp. larvae (Nematoda, Dioctophymatoidea) parasite of Rhinella marina (Amphibia: Bufonidae) from Eastern Amazonia. Revista Brasileira de Parasitologia Veterinária, Jaboticabal, v. 25, n. 2, p. 235-239, Jun 2016.

NEVES, D. P. Parasitologia humana. 11.ed. São Paulo: Atheneu, 2005.

OLIVEIRA, V. J.; TEIXEIRA; R. E. .R.; SANTOS, C. M. R.; SANTANA, I. S. F.; SANTOS, N. F.; MACEDO, E. C.; SILVA, M. D.; ROCHA, A. A.; FRAGA, R. E. Avaliação de parasitas gastrointestinais da avifauna silvestre mantidas em cativeiro no Centro de Triagem de Animais Silvestres em Vitória da Conquista, Bahia. Repositório Institucional UFBA. Bahia. mai 2016.

OMAR, H. M.; OMER, O. H.; AL-DHUBAIBI, M. Gigantobilharzia, Possible Cause of Cercarial Dermatitis: Case Report. International journal of health sciences, Alcacim, v. 10, n. 1, jan./mar. 2016. Disponível em: <https://www.ncbi.nlm.nih.gov/pmc/articles/PMC4791165/>.

OTEGBADE, A.; MORENIKEJI, O. Gastrointestinal parasites of birds in zoological gardens in south-west Nigeria. Tropical biomedicine. v. 31, n. 1, p. 54-62, 2014.

PEREZ-GOMEZ, G.; JIMENEZ-ROCHA, A. E.; BERMUDEZ-ROJAS, T. Parásitos gastrointestinales de aves silvestres en un ecosistema ribereño urbano tropical en Heredia, Costa Rica. Revista de Biologia Tropical. v. 66, n. 2, 2018.

PINTO, H. A.; MATI, V. L. T.; MELO, A. L. Dermatite cercariana por esquistossomatídeos de aves: é possível a ocorrência de casos no Brasil? Revista de Patologia Tropical. 2012; v. 41:1-14.

ROBERTS, L. S.; JANOVY, J. J.; NADLER, S. Foundations of Parasitology. 9.ed. Nova lorque: McGraw-Hill, 2013. 697 p.

Royal Veterinary College [online]. Disponível em: 
https://www.rvc.ac.uk/. Acesso em: 7 nov. 2018.

SANTOS, G. G. C.; MATUELLA, G. A.; CORAIOLA, A. M.; SILVA, L. C. S.; LANGE, R. R.; SANTIN E. Doenças de aves selvagens diagnosticadas na Universidade Federal do Paraná (2003-2007). Pesquisa Veterinária Brasileira, Rio de Janeiro, v. 28, n. 11, p. 565-570, nov. 2008.

SANTOS, P. M. S.; SILVA, S. G. N.; FONSECA, C. F.; OLIVEIRA, J. B. Parasitos de aves e mamíferos silvestres em cativeiro no estado de Pernambuco. Pesquisa Veterinária Brasileira, v. 35, n. 9, p. 788-794, set. 2015. Disponível em: < https://bit.ly/2JwJCFM > DOI: 10.1590/S0100-736X2015000900004.

SCHMIDT, R. E.; REAVILL, D. R.; PHALEN, D. N. Pathology of Pet and Aviary Birds. 2.ed. Singapura: Wiley Blackwell, 2015. 299 p.

SKIRNISSON, K.; KOLAROVA, L. Diversity of bird schistosomes in anseriform birds in Iceland based on egg measurements and egg morphology. Parasitology research, v. 103, n. 1, p. 43-50, 2008. Disponível em: < https://bit.ly/2WywP9f> DOI: $10.1007 / \mathrm{s} 00436-008-0925-4$

SNAK, A.; LENZI, P. F.; AGOSTINI, K. M.; DELGADO, L. E.; MONTANUCCI, C. R.; ZABOTT, M. V. Coproparasitological analysis of captive wild birds. Ciência Animal Brasileira. Goiânia, v.15, n.4, p. 502-507, out./dez. 2014.

SPALDING, M. G.; FORRESTER D. J. Pathogenesis of Eustrongylides ignotus (Nematoda: Dioctophymatoidea) in Ciconiiformes. Journal of Wildlife Diseases, v. 29, n. 2, 250-260, abr. 1993. Disponível em: <https://www.ncbi.nlm.nih.gov/pubmed/8487374> DOI: 10.7589/0090-3558-29.2.250.

TAYLOR, M. A.; COOP, R. L.; WALL, R. L. Veterinary Parasitology. 4.ed. Chichester: Wiley Blackwell, 2016. 1006 p.

TIERSCH, K. M.; SAMSON-HIMMELSTJERNA, G. V.; GAULY, M. The role of culture media on embryonation and subsequent infectivity of Capillaria obsignata eggs. Parasitology Research [online]. Alemanha, 2012. Disponível em: https://bit.ly/2Q5I5Lr. Acesso em: 2 nov. 2018.

TORTORA, G. J.; FUNKE, B. R.; CASE, C. L. Microbiologia. 12.ed. Porto Alegre: Artmed, 2017. 964 p.

TULLY, T. N.; DORRESTEIN, G. M.; JONES, A. K. Clínica de aves. 2.ed. Rio de Janeiro: Elsevier, 2010. 344 p.

URQUHART, G.M.; ARMOUR, J.; DUNCAN, J.L.; DUNN, A. M.; JENNINGS, F. W. Parasitologia Veterinária. 2.ed. Rio de Janeiro: Guanabara Koogan, 1998. 273p. VAZ, F. F., SILVA, L. A. F.; FERREIRA, V. L.; SILVA, R. J.; RASO, T. F. Gastrointestinal helminths of two populations of wild pigeons (Columba livia) in Brazil. Revista Brasileira de Parasitologia Veterinária, 26(4), 446-450. 2017. 
Web Atlas of Medical Parasitology [online]. The Korean Society for Parasitology, Coreia. Disponível em: http://atlas.or.kr/about/index.html. Acesso em: 10 nov. 2018.

ZAJAC, A. M.; CONBOY, G. A. Veterinary Clinical Parasitology. 8.ed. lowa: WileyBlackwell, 2012. 354 p. 